\title{
Acute torsion of a wandering spleen: a paediatric emergency
}

\author{
Sachit Anand, ${ }^{1}$ Devendra Kumar Yadav, ${ }^{2}$ Shilpa Sharma, ${ }^{1}$ Abhimanyu Varshney ${ }^{1}$
}

'Department of Paediatric Surgery, All India Institute of Medical Sciences, New Delhi, India

${ }^{2}$ Department of Pediatric Surgery, Vardhman Mahavir Medical College and Safdarjung Hospital, New Delhi, India

Correspondence to Dr Abhimanyu Varshney, drabhimanyu1989@gmail.com

Accepted 2 June 2018
Check for updates

To cite: Anand S, Yadav DK, Sharma S, et al. BMJ Case Rep Published Online First: [please include Day Month Year]. doi:10.1136/bcr-2018 225496

\section{DESCRIPTION}

A 5-year-old boy presented to the emergency department with intense dull aching pain in the left lower abdomen. On physical examination, his vitals were stable. A well-defined, tender, firm, $10 \times 6 \mathrm{~cm}$ sized mass was palpable in the left lower abdomen occupying the left hypochondrium, left lumbar and umbilical regions. Urgent ultrasound revealed the absence of spleen in the normal position with a hypoechoic encapsulated mass in the left lower abdomen while Doppler study showed the absence of internal vascularity in it. Contrast-enhanced CT (CECT) of the abdomen (figure 1A,B) confirmed the presence of an enlarged, minimally enhancing and inferiorly displaced spleen with characteristic 'whirled appearance' of the splenic hilum. The diagnosis of splenic torsion was confirmed and an exploratory laparotomy was performed. Intraoperatively, the spleen was torsed 720 degrees on its pedicle with an engorged and thrombosed splenic vein (figure 2A,B). The ligamentous attachments (gastrosplenic, splenocolic, splenophrenic and splenorenal) of spleen were absent leading to an inferiorly displaced wandering spleen. After an unsuccessful attempt to preserve the spleen with counter-clockwise detorsion of the pedicle, splenectomy was performed. The child had an uneventful recovery and was discharged on the fourth postoperative day.

Wandering spleen is a rare condition accounting for less than $0.25 \%$ of all splenectomies. It can either occur due to congenital absence of suspensory ligaments of spleen or due to an acquired laxity of these ligaments. ${ }^{1}$ Acute abdominal pain due to torsion followed by an abdominal mass are the most common clinical presentations in children. ${ }^{2}$ The presence of a comma-shaped spleen at an abnormal location on ultrasound along with absence of internal vascularity on Doppler in a symptomatic child are characteristic features for torsion of a
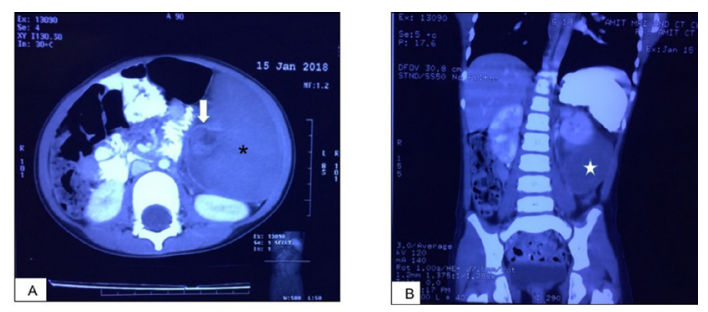

Figure 1 Contrast-enhanced CT scan of the abdomen showing a whirled appearance of the twisted splenic pedicle, that is, whirl sign (arrow in A) and a nonenhancing infarcted spleen (asterisk in A). These features with an inferiorly displaced ectopic spleen (star in B) in the left lumbar region are characteristic of torsion of a wandering spleen.
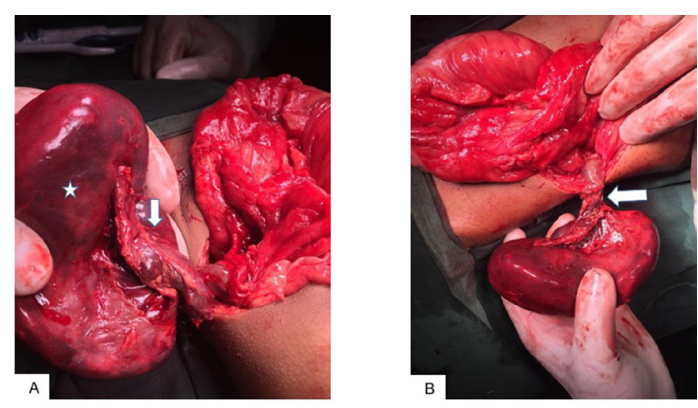

Figure 2 Intraoperative appearance of a twisted splenic pedicle (solid arrows in A and B) and an infarcted spleen (asterisk in A).

wandering spleen. At times, these features can be obscured by bowel gas. Thus, a CECT scan of the abdomen is an excellent alternative in these conditions and can provide a better delineation of the whirled (twisted) splenic pedicle. ${ }^{3}$ The decision of splenopexy versus splenectomy depends on the success of detorsion and viability of spleen.

\section{Learning points}

- Wandering spleen is a rare clinical entity with the presence of an abnormally positioned hypermobile spleen.

- Children with wandering spleen can have a variable clinical presentation from an incidental diagnosis at one end of the spectrum to an acute abdomen due to torsion at the other end.

- When torsed, splenectomy should be performed in conditions of massive splenic infarction and/ or splenic vein thrombosis.

Contributors The case was admitted and operated on under the care of DKY at All India Institute of Medical Sciences (AlIMS). The manuscript was written by SA and AV. Final revision of the manuscript was done by SS. All authors have approved the submission of the revised version.

Funding The authors have not declared a specific grant for this research from any funding agency in the public, commercial or not-for-profit sectors.

Competing interests None declared.

Patient consent Parental/guardian consent obtained.

Provenance and peer review Not commissioned; externally peer reviewed.

(C) BMJ Publishing Group Ltd (unless otherwise stated in the text of the article) 2018. All rights reserved. No commercial use is permitted unless otherwise expressly granted.

\section{REFERENCES}

1 Ben Ely A, Seguier E, Lotan G, et al. Familial wandering spleen: a first instance. J Pediatr Surg 2008;43:e23-5. 


\section{Images in...}

2 Brown CV, Virgilio GR, Vazquez WD. Wandering spleen and its complications in children: a case series and review of the literature. J Pediatr Surg 2003;38:1676-9.

3 El Bouhaddouti H, Lamrani J, Louchi A, et al. Torsion of a wandering spleen. Saudi J Gastroenterol 2010;16:288-91.

Copyright 2018 BMJ Publishing Group. All rights reserved. For permission to reuse any of this content visit

http://group.bmj.com/group/rights-licensing/permissions.

BMJ Case Report Fellows may re-use this article for personal use and teaching without any further permission.

Become a Fellow of BMJ Case Reports today and you can:

- Submit as many cases as you like

- Enjoy fast sympathetic peer review and rapid publication of accepted articles

Access all the published articles

- Re-use any of the published material for personal use and teaching without further permission

For information on Institutional Fellowships contact consortiasales@bmjgroup.com

Visit casereports.bmj.com for more articles like this and to become a Fellow 